\title{
Human Metastasis Regulator Protein H-Prune is a Short-Chain Exopolyphosphatase ${ }^{\dagger}$
}

\author{
Marko Tammenkoski, ${ }^{\ddagger}$ Katja Koivula, ${ }^{*}$ Emilio Cusanelli," Massimo Zollo," Clemens Steegborn, ${ }^{\S}$ \\ Alexander A. Baykov, ${ }^{*, \perp}$ and Reijo Lahti*,*

\begin{abstract}
Department of Biochemistry, University of Turku, FIN-20014 Turku, Finland, Department of Biochemistry and Biotechnological Medicine, Via Pansini 5, University Federico II of Naples, Italy, c/o CEINGE, Centro di Ingegneria Genetica e Biotecnologie Avanzate, Naples, Italy, Department of Physiological Chemistry, Ruhr-University Bochum, 44801 Bochum, Germany, and A. N. Belozersky Institute of Physico-Chemical Biology, Moscow State University, Moscow 119899, Russia
\end{abstract}

Received June 9, 2008; Revised Manuscript Received July 24, 2008

\begin{abstract}
The DHH superfamily human protein h-prune, a binding partner of the metastasis suppressor $\mathrm{nm} 23-\mathrm{H} 1$, is frequently overexpressed in metastatic cancers. From an evolutionary perspective, h-prune is very close to eukaryotic exopolyphosphatases. Here, we show for the first time that h-prune efficiently hydrolyzes short-chain polyphosphates $\left(k_{\mathrm{cat}}\right.$ of $\left.3-40 \mathrm{~s}^{-1}\right)$, including inorganic tripoly- and tetrapolyphosphates and nucleoside $5^{\prime}$-tetraphosphates. Long-chain inorganic polyphosphates ( $\geq 25$ phosphate residues) are converted more slowly, whereas pyrophosphate and nucleoside triphosphates are not hydrolyzed. The reaction requires a divalent metal cofactor, such as $\mathrm{Mg}^{2+}, \mathrm{Co}^{2+}$, or $\mathrm{Mn}^{2+}$, which activates both the enzyme and substrate. Notably, the exopolyphosphatase activity of h-prune is suppressed by $\mathrm{nm} 23-\mathrm{H} 1$, longchain polyphosphates and pyrophosphate, which may be potential physiological regulators. Nucleoside triphosphates, diadenosine hexaphosphate, cAMP, and dipyridamole (inhibitor of phosphodiesterase) do not affect this activity. Mutation of seven single residues corresponding to those found in the active site of yeast exopolyphosphatase led to a severe decrease in h-prune activity, whereas one variant enzyme exhibited enhanced activity. Our results collectively suggest that prune is the missing exopolyphosphatase in animals and support the hypothesis that the metastatic effects of h-prune are modulated by inorganic polyphosphates, which are increasingly recognized as critical regulators in cells.
\end{abstract}

H-prune, ${ }^{1}$ a $50 \mathrm{kDa}$ protein, is a human ortholog of Drosophila prune, which is so-named for the brownish-purple eye color induced by its mutation in the fly. Overexpression of h-prune is associated with cancer progression, tumor aggressiveness, and advanced disease status in breast and gastric cancers $(1,2)$. The protein interacts physically with a known suppressor of cancer metastasis, $\mathrm{nm} 23-\mathrm{H} 1$, and inhibits its antimetastatic function in vivo (3). Moreover, h-prune participates in a complex network of interactions with proteins involved in cell cycle and motility $(4,5)$, stimulates invasion via contacts with gelsolin, an ATP-

${ }^{\dagger}$ This work was supported by Academy of Finland Grants 201611 and 114706, Russian Foundation for Basic Research Grant 06-04-48887, and grants from the Ministry of Education and the Academy of Finland (for the National Graduate School in Informational and Structural Biology), AIRC, SEMM (E.C.), Fondazione alla lotta del Neuroblastoma, EU-FP6 EET-Pipeline and EU-FP7-TuMic grants.

* To whom correspondence may be addressed. Tel.: 7-495-9395541 (A.A.B.); 358-2-333-6845 (R.L.). Fax: 7-495-939-3181 (A.A.B.); 358-2-333-6860 (R.L.). E-mail: baykov@genebee.msu.su (A.A.B.); reijo.lahti@utu.fi. (R.L.).

\#niversity of Turku.

"CEINGE.

${ }^{\S}$ Ruhr-University Bochum.

${ }^{\perp}$ Moscow State University.

${ }^{1}$ Abbreviations: $\mathrm{AP}_{4}$, adenosine 5 '-tetraphosphate; $\mathrm{GP}_{4}$, guanosine 5'-tetraphosphate; h-prune, human prune; $\mathrm{P}_{3}$, tripolyphosphate; $\mathrm{P}_{4}$, tetrapolyphosphate; $\mathrm{P}_{25}, \mathrm{P}_{45}$, and $\mathrm{P}_{65}$, linear inorganic polyphosphates containing on the average 25,45 , and 65 phosphate residues, respectively; PPase, inorganic pyrophosphatase; PPX, exopolyphosphatase; scPPX, Saccharomyces cerevisiae exopolyphosphatase. severing protein acting in focal adhesion (5), and regulates the disassembly of focal adhesions to promote cell migration in cooperation with glycogen synthase kinase-3 (6). All these pathways promote cancer metastasis (7).

H-prune belongs to the DHH superfamily named after the characteristic Asp-His-His motif in the N-terminal region of member proteins $(8)$. This superfamily comprises $>1000$ members and is further divided into families 1 and 2, based on conserved motifs in the $\mathrm{C}$-terminal region. H-prune belongs to family 2, which contains a DHHA2 (DHHassociated type 2) C-terminal domain with two characteristic motifs, DxK and xRKx (8). Several members of the DHH superfamily exhibit phosphohydrolase activity, including nuclease RecJ (9) belonging to family 1 and exopolyphosphatase $(10)$ and pyrophosphatase $(11,12)$, members of family 2, similar to h-prune. Earlier studies showed low phosphodiesterase activity of h-prune in vitro (3).

Here, we demonstrate that, consistent with its evolutionary position, h-prune has a hitherto unrecognized high exopolyphosphatase activity, which exceeds its phosphodiesterase activity by 4 orders of magnitude and is inhibited by nm23H1. Experiments on substrate specificity, metal cofactor requirements and sensitivity to point mutations reveal that this new activity closely resembles that of other known exopolyphosphatases. Our findings implicate polyphosphates as regulators of h-prune metastatic function in cells. 


\section{EXPERIMENTAL PROCEDURES}

Materials. Pentasodium tripolyphosphate was purchased from Fluka, and hexaammonium tetrapolyphosphate was acquired from Sigma. Tetra(triethylammonium) adenosine 5 '-tetraphosphate $\left(\mathrm{AP}_{4}\right)$ was obtained from Jena Bioscience. Dipyridamole, Tris salts of guanosine $5^{\prime}$-tetraphosphate $\left(\mathrm{GP}_{4}\right)$ and GTP, disodium ATP, sodium cAMP, long-chain inorganic polyphosphates $\mathrm{P}_{25}, \mathrm{P}_{45}$, and $\mathrm{P}_{65}$ (sodium phosphate glass types 25,45 , and 65 ), and ammonium salt of $\mathrm{P}^{1}, \mathrm{P}^{6}$ diadenosine 5'-hexaphosphate were obtained from SigmaAldrich. Orthophosphate and short-chain polyphosphate contamination of $\mathrm{P}_{25}, \mathrm{P}_{45}$, and $\mathrm{P}_{65}$ was eliminated by gel filtration on a $0.8 \times 26 \mathrm{~cm}$ Bio-Gel P-2 column (Bio-Rad). Each polyphosphate $(20 \mathrm{mg})$ was applied to the column in $2 \mathrm{~mL}$ of $0.1 \mathrm{M}$ Tris-HCl buffer, $\mathrm{pH}$ 7.2. Eluted fractions were analyzed for $\mathrm{P}_{\mathrm{i}}$ before and after boiling for $20 \mathrm{~min}$ with $3 \mathrm{M}$ hydrochloric acid. Polyphosphate concentrations mentioned below were determined on the basis of polymer molecular masses. The metastasis suppressor protein, nm23H1, was produced in Escherichia coli and isolated, as described by Middelhaufe et al. (13).

Expression and Purification of H-Prune. Cloning of h-prune from MGC human full-length cDNA has been described in a previous report (13). Mutations were introduced using the QuikChange site-directed mutagenesis kit (Stratagene), and verified by sequencing. His-tagged wildtype and variant $\mathrm{h}$-prune pET151 constructs were transformed into E. coli Rosetta 2 strain and expressed in Overnight Express Instant TB medium (Novagen). Cells were grown for $24 \mathrm{~h}$ at room temperature and kept on ice for $15 \mathrm{~min}$ before harvesting by centrifugation at $5000 \mathrm{rpm}$ for $20 \mathrm{~min}$ at $4{ }^{\circ} \mathrm{C}$. Sedimented cells were stored at $-20{ }^{\circ} \mathrm{C}$. For protein purification, frozen cells $(8 \mathrm{~g})$ were melted on ice, and suspended in $40 \mathrm{~mL}$ of buffer A $(50 \mathrm{mM}$ Tris/ $\mathrm{HCl}, \mathrm{pH} 7.8$, $0.5 \mathrm{M} \mathrm{NaCl}$ ) supplemented with a small amount of DNase I (Roche) and $1 \mathrm{mM}$ phenylmethanesulfonyl fluoride (Fluka). Next, cells were disrupted twice with the French Press at $15000 \mathrm{psi}$, and the debris removed by centrifugation at 20000 rpm for $30 \mathrm{~min}$ at $4{ }^{\circ} \mathrm{C}$. H-prune was isolated from the supernatant by metal chelate chromatography on a Talon column (BD Biosciences) and gel filtration on a Superdex 200 column, as described previously (13). This procedure yielded 4-10 $\mathrm{mg}$ of electrophoretically pure h-prune per liter of cell culture (approximately $30 \mathrm{~g}$ cell paste). Concentrations of h-prune solutions were determined on the basis of a subunit molecular mass of $50 \mathrm{kDa}$ and extinction coefficient, $\epsilon^{1 \%}{ }_{280}$, of 2.7 (estimated from the amino acid composition using ProtParam).

Activity Measurements. Rates of $\mathrm{P}_{3}, \mathrm{P}_{25}, \mathrm{P}_{45}$, and $\mathrm{P}_{65}$ hydrolysis were determined from continuous recordings of $\mathrm{P}_{\mathrm{i}}$ liberation using an automatic $\mathrm{P}_{\mathrm{i}}$ analyzer (14). Reactions were initiated by adding a suitable aliquot of enzyme solution, and performed at $25^{\circ} \mathrm{C}$. The assay buffer contained $0.1 \mathrm{M}$ Tris $/ \mathrm{HCl}, \mathrm{pH} 7.2,50 \mu \mathrm{M}$ EGTA, and the indicated concentrations of substrates and divalent metal cofactors (added as chlorides). To maintain constant ionic strength in assays utilizing 10 and $30 \mathrm{mM} \mathrm{Mg}{ }^{2+}$, the Tris/ $\mathrm{HCl}$ concentrations were lowered to 0.07 and $0.01 \mathrm{M}$, respectively. The activity of h-prune on $\mathrm{P}_{4}, \mathrm{AP}_{4}, \mathrm{GP}_{4}$, and other nucleotides was determined with a fixed-time assay using Biomol Green phosphate reagent (Biomol, Germany). Using this method,
Scheme 1: $\mathrm{Mg}^{2+}$ Dependence of $\mathrm{P}_{3}$ Hydrolysis by H-Prune

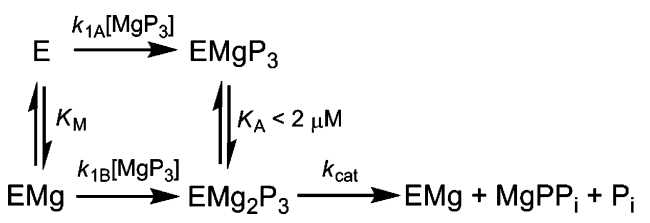

the reaction was performed for $20-120 \mathrm{~s}$ in a volume of 50 $\mu \mathrm{L}$ on a microtiter plate, $100 \mu \mathrm{L}$ of the Biomol Green reagent were added, and color measured at $620 \mathrm{~nm}$ after $25 \mathrm{~min}$ incubation. The reported activity values are precise within a margin of $\pm 10 \%$.

Phosphodiesterase activity was determined with a cyclic nucleotide phosphodiesterase assay kit (Biomol) according to the manufacturer's manual. In this assay, AMP formed from cAMP was consumed by $5^{\prime}$-nucleotidase, and phosphate liberated determined with Biomol Green reagent. Bovine brain phosphodiesterase provided with the kit was employed as the positive control.

Calculations. The total concentrations of $\mathrm{MgCl}_{2}$ and $\mathrm{P}_{3}$ required to maintain the desired levels of free $\mathrm{Mg}^{2+}$ ion and $\mathrm{MgP}_{3}$ complex at $\mathrm{pH} 7.2$ were calculated using the dissociation constants $K_{1}=3.63 \mu \mathrm{M}$ and $K_{2}=1.91 \mathrm{mM}$ for the $\mathrm{MgP}_{3}$ and $\mathrm{Mg}_{2} \mathrm{P}_{3}$ complexes, respectively (15). To convert the Michaelis constant obtained in terms of $\mathrm{MgP}_{3}$ concentration into that in terms of total $\mathrm{P}_{3}$ concentration, the former constant was divided by $\left(1+[\mathrm{Mg}] / K_{2}+K_{1} /[\mathrm{Mg}]\right)$, where $[\mathrm{Mg}]$ is free $\mathrm{Mg}^{2+}$ concentration. The dependence of the rate of $\mathrm{P}_{3}$ hydrolysis on $\left[\mathrm{Mg}^{2+}\right]$ and $\left[\mathrm{MgP}_{3}\right]$ was analyzed from Scheme 1 derived earlier for $s c$ PPX (15), whereby $k_{1 \mathrm{~A}}$ and $k_{1 \mathrm{~B}}$ are second-order rate constants for $\mathrm{MgP}_{3}$ binding, $K_{\mathrm{M}}$ and $K_{\mathrm{A}}$ are the dissociation constants for metal binding and $k_{\text {cat }}$ is the catalytic constant. Due to the high processivity of PPX, the substrate-binding step is assumed to be essentially irreversible. Consequently, the $k_{\text {cat }} / K_{\mathrm{m}}$ value approaches the apparent second-order rate constant for substrate binding and depends on the $\mathrm{Mg}^{2+}$ concentration, according to eq 1 (15):

$$
k_{\text {cat }} / K_{\mathrm{m}}=\left(k_{1 \mathrm{~B}}+k_{1 \mathrm{~A}} K_{\mathrm{M}} /[\mathrm{Mg}]\right) /\left(1+K_{\mathrm{M}} /[\mathrm{Mg}]\right)
$$

Inhibition of activity was analyzed with eq 2 , whereby $A$ and $A_{0}$ represent the activities measured in the presence and absence of inhibitor I, respectively, and $\mathrm{IC}_{50}$ is its $50 \%$ inhibitory concentration. Nonlinear least-squares fitting was performed using the program SCIENTIST (MicroMath).

$$
A=A_{0} /\left(1+[I] / \mathrm{IC}_{50}\right)
$$

Bioinformatics Methods. H-prune, scPPX and family II PPase from Streptococcus mutans were used as query sequences in PSI-BLAST searches against known genomes and the NCBI nonredundant amino acid database for prune sequences from incomplete (or nonannotated) genomes. The retrieved sequences were aligned with ClustalW (16). A phylogenetic tree was constructed using the maximum parsimony method and verified by bootstrap analysis (1000 replicates) with MEGA 3.1 (17).

\section{RESULTS}

Sequence Analysis of H-Prune. A PSI-BLAST search of protein databases resulted in 146 sequences belonging to family 2 of the DHH superfamily of proteins, with six conserved motifs containing most of the active site residues 


\begin{tabular}{|c|c|c|c|c|c|c|c|c|}
\hline No. & & $\begin{array}{c}30 \\
\ldots . .1 \ldots\end{array}$ & $\begin{array}{l}105 \\
.1 \ldots\end{array}$ & $\begin{array}{r}130 \\
\ldots .1 .\end{array}$ & $\begin{array}{l}180 \\
\ldots \mid \ldots\end{array}$ & $\begin{array}{r}240 \\
\ldots \ldots 1\end{array}$ & $\begin{array}{r}350 \\
\ldots .1\end{array}$ & \\
\hline 1 & Homo sapiens & -LGNEACDLDST- & $-\mathrm{LVDHH}-$ & -LDHRPIE- & -ILDCVN- & -RKDQKT- & -VSRKKL & $(102)$ \\
\hline 2 & Macaca mulatta & -LGNEACDLDSV- & $-\mathrm{LVDHH}-$ & -LDHRPIE- & -ILDCVN- & -RKDQKT- & -VSRKKL & 102) \\
\hline 3 & Mus musculus & -LGNEACDLDSM- & $-\mathrm{LVDHH}-$ & -LDHRPIE- & -ILDCVN- & -RKDQKT- & -VSRKKL & 103) \\
\hline 4 & Rattus norvegicus & -LGNEACDLDSM- & -LVDHH- & -LDHRPIE- & -ILDCVN- & - RKDQKT- & -VSRKKL & (03) \\
\hline 5 & Bos taurus & -LGNEACDLDSM- & $-\mathrm{LVDHH}-$ & -LDHRPID- & -LLDCVN- & - RKDQKT- & -ISRKKV & $02)$ \\
\hline 6 & Equus caballus & -LGNEACDLDSM- & $-\mathrm{LV}$ & -LDHRPIE- & -ILDCVN- & -RKDQKT- & -VSRKKL & 02) \\
\hline 7 & Canis Iupus & -LGNEACDLDSM- & -LVDHH- & -LDHRPIE- & -ILDCVN- & -RKDQKT- & -VSRKKL & 02) \\
\hline 8 & Erinaceus europaeus & -LGNEACDLDSV- & $-\mathrm{LVDHH}-$ & -LDHRPIE- & -ILDCVN- & -RKDQKI- & -ASRKKL & 02) \\
\hline 9 & Oryctolagus cuniculus & -LGNEACDLDSM- & $\mathrm{OHH}-$ & -LDHRPIE- & -ILDCVN- & -RKDLKT- & -ASRKKL & \\
\hline 10 & Monodelphis domestica & CDLDSM- & $\mathrm{HH}-$ & -LDHRPLE- & -ILD & -RKDLKT- & $-\mathrm{ASR}$ & \\
\hline 11 & Danio rerio & MGNEACDMDSM- & $\mathrm{HN}-$ & -IDHHLLQ- & $-I L D$ & -LKDMKA- & $-\mathrm{ASR}$ & \\
\hline 12 & Takifugu rubripes & CDTDSM- & $-\mathrm{LV}$ & -IDHHLLE- & $-V L I$ & MKS- & $-\mathrm{VSR}$ & \\
\hline 13 & Tetraodon nigroviridis & -LGNEACDVDSM- & -LVDHN- & -IDHHLLE- & $-V L D C V N-$ & -LKDRKS- & -VSRKKL & \\
\hline 14 & Xenopus tropicalis & -LGNEACDLDSM- & -LVDHN- & -IDHRHLE- & -VLDCIN- & -RKDLKV- & $-\mathrm{ASR}$ & 10) \\
\hline 15 & Drosophila melanogaster & -MGNESCDLDSA- & $-\mathrm{LVDHH}-$ & -LDHRPLE- & -VLDTIN- & -RKDMKV- & -ATRKHI & \\
\hline 16 & Drosophila pseudoobscura & -IGNESCDLDSA- & $-\mathrm{LVDHH}-$ & -LDHRPID- & -VLDTVN- & -RKDMKI- & -ATRKHI & \\
\hline 17 & Aedes aegypti & -LGNESCDLDSA- & $-\mathrm{LVDHH}-$ & -VDHRPFD- & -VLDTVN- & -SKDLKI- & -ASRKQL & \\
\hline 18 & Anopheles gambiae & -IGNESCDLDSA- & $-\mathrm{LVDHH}-$ & -VDHRPVE- & -VLDTVN- & -LKDLKI- & -ASRKQL & \\
\hline 19 & Tribolium castaneum & -LGNESCDLDST- & $-\mathrm{LVDHH}-$ & -FDHRTIN- & -IYDTIG- & -YRDLKV- & -LTRKFI & \\
\hline 20 & Ciona intestinalis & -IGNQACDLDSC- & -LLDHH- & -IDHRPIN- & -LVDTDN- & -LKDPKI- & -ATRKQL & 0) \\
\hline 21 * & Trypanosoma cruzi & -LGNDGGDMDSI- & LYDHN & -IDHHFDE- & -VLDTVN- & -RRDYKD- & -VSRKRL & 4) \\
\hline 22 & Leishmania braziliensis & -QGNEGGDMDSI- & LYDHN & -VDHHFDE- & -ILDTVN- & -RRDYKQ- & -ISRKKL & 6) \\
\hline $23 *$ & Leishmania major & -QGNEGGDMDSI- & LYDHN & -VDHHFDE- & $-V L D$ & -RRDYKQ- & -ISRKKL & \\
\hline 24 & Leishmania infantum & -QGNEGGDMDSI- & LYDHN & -VDHHFDE- & $-V L I$ & -RRDYKQ- & -VSRKKL & \\
\hline 25 & Cryptococcus neoformans & -MGNQAGDLDSL- & LVDHN & -IDHHEDE- & $-\mathrm{VIL}$ & -MRDYKE- & -ATRKQV & \\
\hline 26 & Coprinopsis cinerea & -TGNEAGDLDSI- & UDHN & -IDHHEDE- & - LII & -RRDY & -ATRKAV & \\
\hline 27 & Schizosaccharomyces pombe & -SGNESADLDSC- & UDHN & -IDHHKDE- & $-\mathrm{LID}$ & -RRDLKQ- & -ASRKKV & \\
\hline 28 & Yarrowia lipolytic & -SGNESADIDSC- & DHN & -IDHHEDE- & - LIL & - RKD & -ASRKQV & \\
\hline 29 & Saccharomyces cerevisiae & -VGNESADMDSI- & VDNN & -IDHHFDL- & -LID & $-\mathrm{KKD}$ & -ATRKQV & 3) \\
\hline 30 & Ashbya gossypii & -CGNESADLDSV- & DHN & -IDHHEDQ- & -MMDTSK- & - RKDY & -ASRKQI & 1) \\
\hline 31 & Candida glabrata & -CGNESADFDSV- & VDHN & -IDHHADK- & -LLDTAN- & $-\mathrm{RKDY}$ & -SSRKRI & \\
\hline 32 & Kluyveromyces lactis & $-\mathrm{CGNH}$ & DHN & -VDHHKDV- & -LIDTDD- & - RKDY & -MSRKQV & 10) \\
\hline 33 & Pichia stipitis & -TGNQSADMDSV- & $\mathrm{DHC}$ & -IDHHADE- & -LIDTSN- & -RKDYKQ- & -ASRKQV & 17) \\
\hline 34 & Debaryomyces hansenii & -TGNQSADLDSV- & $\mathrm{DHC}$ & -IDHHQDE- & -LIDTSN- & -KKDYKQ- & -ASRKQI & 11) \\
\hline 35 & Candida albicans & -TGNQSADMDSV- & DHN & -IDHHEDE- & -LIDTSG- & -RKDYKQ- & -ASRKQV & 10) \\
\hline 36 & Neurospora crassa & -IGNESADLDSL- & -LVDHN & -IDHHDDE- & -LIDTTN- & -RKDYKR- & -KSRKQV & (14) \\
\hline 37 & Aspergillus nidulans & -IGNPSADLDSI- & -LVDWN & -IDHHADE- & -LIDTAN- & -GRDYKD- & -KSRKQV & (11) \\
\hline & Consensus PPase & $-\times G H \times x P D \times D \times i-$ & & $-\mathrm{XDHH} \times \mathrm{XX}-$ & txx- - & $-x \times D x$ & $-\mathrm{xSRKKq}$ & $(7-1$ \\
\hline
\end{tabular}

FIGURE 1: Partial sequences of 37 PPXs/prunes and consensus sequence of 109 family II PPases. The sequences marked with an asterisk belong to characterized PPXs. Entire enzyme sequences were aligned with ClustalW. Residue numbering is for h-prune. Invariant PPX/ prune residues are shaded in gray, scPPX and PPase polar active site residues are bold-faced. Capital letters represent invariant residues, and small letters show the most frequently occurring residues $(>80 \%)$ in the PPase consensus sequence. The numbers on the right sides of the sequences represent the numbers of the residues in the remaining $\mathrm{C}$-terminal fragments.

identified in PPX (18) and PPase (19, 20). Of these, 109 sequences were identified as PPases, based on sequence length, typically 310 amino acid residues, and the invariant motif HxxP (positions 24-27 in Figure 1) (18). This group includes the six proteins for which PPase activity was demonstrated $(11,12,21)$.

In the second group, comprising 37 longer sequences (370-800 residues), the above-mentioned motif is replaced by $\operatorname{Nxx}(\mathrm{C}, \mathrm{G}, \mathrm{A})$ (Figure 1). This replacement results in a loss of one metal binding site from Saccharomyces cerevisiae PPX ( $s c$ PPX); furthermore, the $\mathrm{N}$ residue is essential for PPX activity, as its conversion to $\mathrm{H}$ reduces PPX activity 500fold (15). The second group includes the three known DHH proteins with PPX activity (marked by the asterisk in Figure 1) $(10,22,23)$ and is less uniform. This group can be divided into two subgroups, based on the length of the C-terminal part and taxonomic considerations. Fourteen vertebrate sequences have long ( $\geq 99$ residues) C-terminal segments (Figure 1). In 23 invertebrates, euglenas and fungi, however, the length of the C-terminal segment does not exceed 34 residues and averages 15 residues, only slightly more than in PPases (Figure 1). The C-terminus is important for classification, inasmuch as it contains binding sites for the metastasis-related proteins $\mathrm{nm} 23-\mathrm{H} 1$ and glycogen synthase kinase-3 in h-prune (13).

A total of 10 mammalian sequences (1-10 in Figure 1), including h-prune, are most closely related, forming a welldefined subfamily. Their characteristic motifs are very similar, as are the overall primary structures (39-98\% pairwise residue identity). The C-terminal parts, following the invariant SRKK motif, are even more similar (75-99\% identity) and of nearly the same length in sequences 1-9. Although the C-terminal part in sequence 10 is much longer, the overlapping parts of the C-termini in sequences 1 and 10 are $60 \%$ identical. Four other vertebrate sequences (11-14 in Figure 1) differ more from h-prune (overall identity 34-50\%; C-terminal identity, 27-37\%). In addition, the DHH motif is found at different locations in these four sequences, more closely resembling known PPXs. In contrast, sequence identity between h-prune and the remaining 23 of the 37 non-PPase sequences does not exceed $25 \%$ (average, $17 \%)$. In the phylogenetic tree, the h-prune subfamily forms a compact group within the non-PPase sequences and is closer to characterized PPXs than to PPases (see Supporting Information, Figure S1).

Exopolyphosphatase Activity of H-Prune. In accordance 
Table 1: Kinetic Parameters for the Hydrolysis of Various Polyphosphates by H-Prune in the Presence of $2 \mathrm{mM} \mathrm{Mg}^{2+}$ or $\mathrm{Co}^{2+}$ as the Cofactor

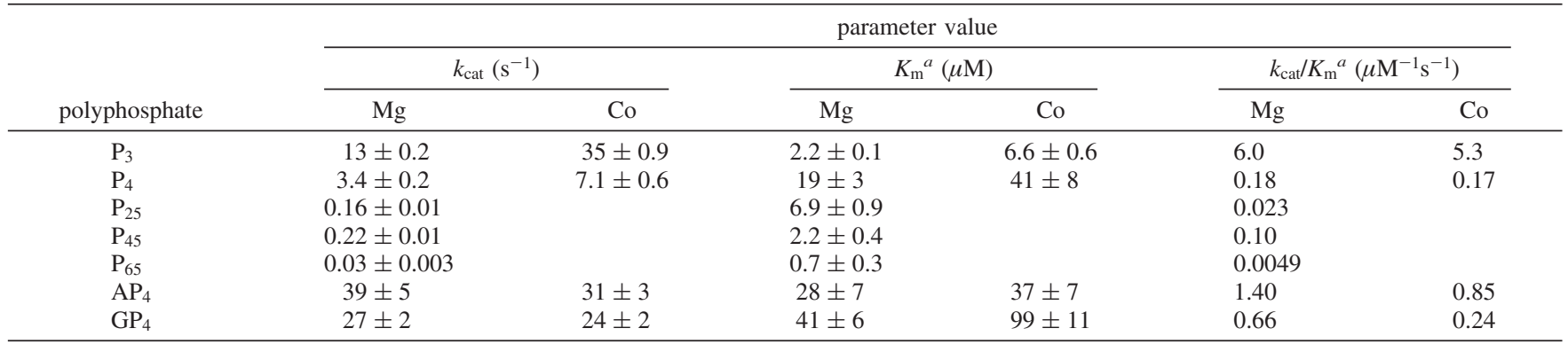

${ }^{a} K_{\mathrm{m}}$ values were obtained in terms of total substrate concentration.

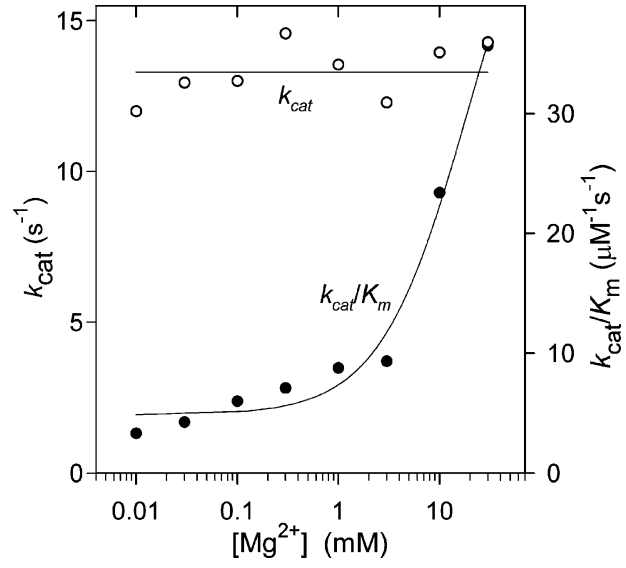

Figure 2: Dependence of $k_{\text {cat }}(\bigcirc)$ and $k_{\text {cat }} / K_{\mathrm{m}}(\bullet)$ values for $\mathrm{P}_{3}$ hydrolysis by h-prune on the free $\mathrm{Mg}^{2+}$ concentration. Enzyme concentration was $5-15 \mathrm{nM}$. $K_{\mathrm{m}}$ values are measured in terms of the $\mathrm{MgP}_{3}$ complex. The $k_{\text {cat }} / K_{\mathrm{m}}$ line shows the best fit for eq 1 .

with its evolutionary position, h-prune degrades linear polyphosphates in the presence of $\mathrm{Mg}^{2+}$ or $\mathrm{Co}^{2+}$ (Table 1). Among the inorganic polyphosphates, the highest $k_{\text {cat }}$ value was observed with $\mathrm{P}_{3}$, which decreased dramatically with an increase in chain length. $\mathrm{AP}_{4}$ and $\mathrm{GP}_{4}$ were hydrolyzed at a higher rate than $\mathrm{P}_{3}$ in the presence of $\mathrm{Mg}^{2+}$ (Table 1), whereas $\mathrm{PP}_{\mathrm{i}}, \mathrm{ATP}, \mathrm{GTP}$, and cAMP were not hydrolyzed significantly (activity $<0.02 \mathrm{~s}^{-1}$ at $50 \mu \mathrm{M}$ substrate). Our estimate of activity against cAMP is consistent with the earlier reported value $\left(0.013 \mathrm{IU} / \mathrm{mg}\right.$ or $\left.0.011 \mathrm{~s}^{-1}\right)$ obtained with a more sensitive assay (3) and is 3500-fold lower than the activity against $\mathrm{P}_{3}$. Our data thus indicate that h-prune is a polyphosphatase and prefers short-chain polyphosphates as substrates.

Exhaustive hydrolysis of $\mathrm{P}_{3}$ in the presence of $\mathrm{Mg}^{2+}$ yielded an equivalent amount of $\mathrm{P}_{\mathrm{i}}$, indicating that the final products are $\mathrm{P}_{\mathrm{i}}$ and $\mathrm{PP}_{\mathrm{i}}$, in agreement with the observation that $\mathrm{PP}_{\mathrm{i}}$ is not hydrolyzed by h-prune. No endopolyphosphatase activity was detected on a urea-PAGE assay (10) using $\mathrm{P}_{25}$ or $\mathrm{P}_{45}$ as substrate (data not shown).

With $\mathrm{P}_{3}$ and $\mathrm{P}_{4}$ as substrates, $\mathrm{Co}^{2+}$ was a better cofactor for h-prune than $\mathrm{Mg}^{2+}$ in terms of $k_{\text {cat }}$ but not $k_{\text {cat }} / K_{\mathrm{m}}$ (Table 1). Among the other cofactors examined, $\mathrm{Mn}^{2+}$ conferred $50 \%$ activity, compared to $\mathrm{Mg}^{2+}$ in $\mathrm{P}_{3}$ and $\mathrm{P}_{4}$ hydrolysis by h-prune.

Kinetics of $\mathrm{P}_{3}$ Hydrolysis in the Presence of $\mathrm{Mg}^{2+}$. The $k_{\text {cat }}$ value $\left(13.3 \pm 0.9 \mathrm{~s}^{-1}\right)$ of h-prune activity was virtually independent of the $\mathrm{Mg}^{2+}$ concentration in the range of 0.01-10 mM (Figure 2), but no hydrolysis of $\mathrm{P}_{3}$ was observed in the absence of the metal cofactor. In contrast, the $k_{\text {cat }} / K_{\mathrm{m}}$ value was markedly increased with $\left[\mathrm{Mg}^{2+}\right.$ ] (Figure 2). The $\mathrm{Mg}^{2+}$ dependence of catalysis may be effectively described by Scheme 1, earlier derived for $s c$ PPX (15). According to this scheme, the preferred substrate for h-prune is $\mathrm{MgP}_{3}$ (tripolyphosphate with one bound metal ion), and catalysis occurs only when another metal ion is bound to the enzyme. The constancy of $k_{\text {cat }}$ in the $\mathrm{Mg}^{2+}$ concentration range examined indicates that the metal binding constant, $K_{\mathrm{A}}$, is small $(<2 \mu \mathrm{M})$. The values for other parameters obtained by fitting the data from Figure 2 to eq 1 were as follows: $k_{1 \mathrm{~A}}=4.8 \pm 0.8 \mu \mathrm{M}^{-1} \mathrm{~s}^{-1}, k_{1 \mathrm{~B}}=56 \pm 9 \mu \mathrm{M}^{-1} \mathrm{~s}^{-1}$, and $K_{\mathrm{M}}=19 \pm 7 \mathrm{mM}$. The results imply that binding of metal ion at the active site accelerates substrate binding $\left(k_{1 \mathrm{~B}}\right.$ $>k_{1 \mathrm{~A}}$ ). In addition, bound substrate enhances enzyme affinity for the metal ion $\left(K_{\mathrm{A}}<K_{\mathrm{M}}\right)$. The $k_{\mathrm{cat}}$ value measured in the presence of $1 \mathrm{mM} \mathrm{Mg}{ }^{2+}$ increased 2-fold with temperature in the range of 25 to $40{ }^{\circ} \mathrm{C}$.

In addition to its activator role, $\mathrm{Mg}^{2+}$ stabilizes h-prune against inactivation during storage. Incubation of $\mathrm{h}$-prune $(1-100 \mu \mathrm{M})$ for $5 \mathrm{~h}$ at $0{ }^{\circ} \mathrm{C}$ in the presence of $0.1 \mathrm{M}$ Tris/ $\mathrm{HCl}, \mathrm{pH} 7.2$, and $50 \mu \mathrm{M}$ EGTA inactivated the enzyme 2-4fold. In contrast, no inactivation was evident in the presence of $1 \mathrm{mM} \mathrm{Mg}^{2+}$.

Active Site Mutations. The purpose of the mutations was 2 -fold. First, we aimed to check the effects of "compensating" mutations, i.e., those that replace h-prune residues with residues found in known PPases and PPXs (Asn-24, His107, His-108, Arg-128). The second goal was to check whether residues corresponding to those important in PPase and PPX (Asp-28, Asp-106, Asp-179, Arg-348) are similarly important in h-prune. The residues corresponding to h-prune Asp-28, Asp-106, and Asp-179 are ligands for the catalytic metal ions in PPase and/or PPX, and the equivalent of Arg348 (located in the more variable C-terminal domain) participates in substrate binding in PPase $(18-20)$. In these cases, mutations were designed to reduce the functionality of a residue $(\mathrm{D} \rightarrow \mathrm{A}, \mathrm{R} \rightarrow \mathrm{A})$.

Eight single variants were therefore constructed, specifically, N24H, D28A, D106A, H107N, H108N, R128H, D179A, and R348A. The N24H, D28A, D179A, and R348A variants were virtually inactive $\left(<0.5 \%\right.$ wild-type $k_{\mathrm{cat}} / K_{\mathrm{m}}$ in $\mathrm{Mg}^{2+}$-stimulated $\mathrm{P}_{3}$ hydrolysis), and D106A, H107N, and H108N proteins displayed reduced but measurable activity ( $k_{\text {cat }}$ values of $35,4.4$, and 32\%, respectively). In contrast, an enhanced $k_{\text {cat }}$ value $(146 \%)$ was obtained with the R128H mutant protein, compared to its wild-type counterpart. $K_{\mathrm{m}}$ value increased 7-fold with the $\mathrm{H} 107 \mathrm{~N}$ and 21-fold with the $\mathrm{R} 128 \mathrm{H}$ variants and was only slightly affected with the other two variants (Table 2). These data indicated that h-prune 
Table 2: Kinetic Parameters for the Hydrolysis of $\mathrm{P}_{3}$ by H-Prune Variants in the Presence of $2 \mathrm{mM} \mathrm{Mg}^{2+}$ as Cofactor

\begin{tabular}{lccc}
\hline & \multicolumn{3}{c}{ parameter value } \\
\cline { 2 - 4 } enzyme & $k_{\text {cat }}\left(\mathrm{s}^{-1}\right)$ & $K_{\mathrm{m}}(\mu \mathrm{M})^{a}$ & $k_{\text {cat }} / K_{\mathrm{m}}\left(\mu \mathrm{M}^{-1} \mathrm{~s}^{-1}\right)^{a}$ \\
\hline wild type & $13 \pm 0.2$ & $2.2 \pm 0.1$ & 6.0 \\
D106A & $4.6 \pm 0.2$ & $1.2 \pm 0.3$ & 3.9 \\
H107N & $0.57 \pm 0.10$ & $15 \pm 12$ & 0.039 \\
H108N & $4.2 \pm 0.1$ & $2.6 \pm 0.2$ & 1.6 \\
R128H & $19 \pm 0.6$ & $46 \pm 3$ & 0.43 \\
\hline
\end{tabular}

${ }^{a} K_{\mathrm{m}}$ values were obtained in terms of total substrate concentration.

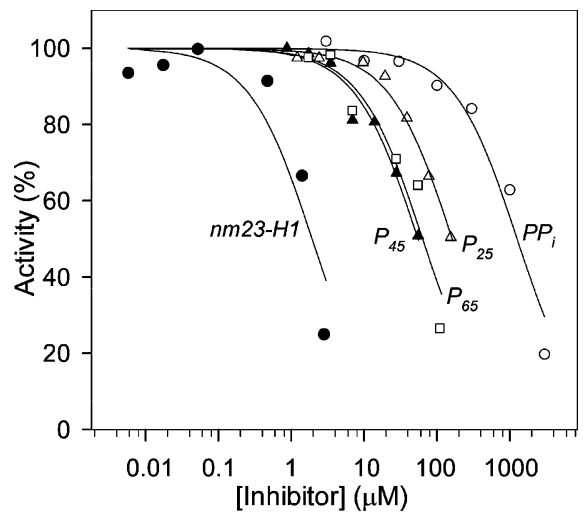

FIGURE 3: Inhibition of h-prune-catalyzed P3 hydrolysis by nm23$\mathrm{H} 1(\bullet), \mathrm{PP}_{\mathrm{i}}(\mathrm{O}), \mathrm{P}_{25}(\Delta), \mathrm{P}_{45}(\boldsymbol{\Delta})$, and $\mathrm{P}_{65}(\square)$ measured at $10 \mu \mathrm{M}$ $\mathrm{P}_{3}$. The total $\mathrm{Mg}^{2+}$ concentration used was $2 \mathrm{mM}$, and enzyme concentration was $52 \mathrm{nM}(\mathrm{nm} 23-\mathrm{H} 1)$ or 4-11 $\mathrm{nM}$ (other inhibitors). Lines were obtained with eq 2 , using the $\mathrm{IC}_{50}$ values shown in Table 3. Activity with no added inhibitors $\left(10 \mathrm{~s}^{-1}\right)$ was taken as $100 \%$.

has low sensitivity to substitutions in the DHH $\cdots$ DHR motif pair, casting doubt on the validity of previous classifications of the DHH proteins based on these two motifs $(3,18)$. The effects of substitutions in other motifs parallel those in PPX and PPase $(15,24,25)$ and suggest a common reaction mechanism.

Inhibitors. Long-chain polyphosphates (poor substrates of h-prune) and $\mathrm{PP}_{\mathrm{i}}$ inhibited h-prune-catalyzed hydrolysis of $\mathrm{P}_{3}$ (Figure 3). Two lines of evidence rule out the possibility that these effects result from $\mathrm{Mg}^{2+}$ chelation by added polyphosphates. First, calculations from published complex stability constants (26) show that the concentration of free $\mathrm{Mg}^{2+}$ in the assay system containing $3 \mathrm{mM} \mathrm{PP}$ (the most unfavorable case) drops from $2 \mathrm{mM}$ to about $0.2 \mathrm{mM}$. Based in Figure 2, this will result in a less than 5\% change in h-prune activity. Second, the $\mathrm{P}_{25}$ inhibition profile was not significantly affected when $\mathrm{Mg}^{2+}$ concentration was increased to $10 \mathrm{mM}$ (data not shown).

The $\mathrm{IC}_{50}$ values derived from Figure 3 decreased markedly from $\mathrm{PP}_{\mathrm{i}}$ to $\mathrm{P}_{25}$, less markedly from $\mathrm{P}_{25}$ to $\mathrm{P}_{45}$, and leveled off with $\mathrm{P}_{65}$ (Table 3 ). Similar dependence of the inhibitory power of polyphosphates on length was observed at a ten times higher $\mathrm{P}_{3}$ concentration (Table 3 ), but $\mathrm{IC}_{50}$ values were higher, pointing to a competition between $\mathrm{P}_{3}$ and other polyphosphates for active site binding. However, the $\mathrm{IC}_{50}$ values measured at $10 \mu \mathrm{M} \mathrm{P}_{3}$ were 3-4 times higher than expected for a competitive inhibition mechanism, based on the $K_{\mathrm{m}}$ values found in Table 1 . This result may be attributed to slow conversion of long-chain polyphosphates.

$\mathrm{ZnCl}_{2}$, which is known to inhibit exopolyphosphatases from different sources $(22,23)$, inhibited h-prune with an
Table 3: $\mathrm{IC}_{50}$ Values for Various Suppressors in the Presence of $2 \mathrm{mM}$ Free $\mathrm{Mg}^{2+}$ and 10 or $100 \mu \mathrm{M}$ Total $\mathrm{P}_{3}$

\begin{tabular}{lcc}
\hline & \multicolumn{2}{c}{$\mathrm{IC}_{50}(\mu \mathrm{M})$} \\
\cline { 2 - 3 } inhibitor & $10 \mu \mathrm{M} \mathrm{P}_{3}$ & $100 \mu \mathrm{M} \mathrm{P}_{3}$ \\
\hline $\mathrm{PP}_{\mathrm{i}}$ & $1200 \pm 200$ & $5700 \pm 600$ \\
$\mathrm{P}_{25}$ & $163 \pm 10$ & $330 \pm 40$ \\
$\mathrm{P}_{45}$ & $55 \pm 7$ & $120 \pm 20$ \\
$\mathrm{P}_{65}$ & $64 \pm 17$ & $105 \pm 11$ \\
$\mathrm{~nm} 23-\mathrm{H} 1$ & $1.9 \pm 0.7$ & $7.2 \pm 0.9$ \\
$\mathrm{~nm} 3-\mathrm{H} 1^{a}$ & $>10$ & \\
\hline${ }^{a}$ Measured in the presence of $60 \mu \mathrm{M} \mathrm{P}_{25}$.
\end{tabular}

$\mathrm{IC}_{50}$ of $32 \pm 2 \mu \mathrm{M}$ under the experimental conditions used to obtain the data of Figure 3. In contrast, ATP, GTP, diadenosine hexaphosphate, and cAMP $(300 \mu \mathrm{M})$ had no significant effects on $\mathrm{P}_{3}$ hydrolysis, implying that these nucleotides are not effectively bound $\left(\mathrm{IC}_{50}>1 \mathrm{mM}\right)$ to the h-prune active site at this concentration. Low affinity of h-prune to diadenosine hexaphosphate is consistent with the inability of h-prune to catalyze endopolyphosphatase reaction. Similarly, $100 \mu \mathrm{M}$ dipyridamole, a known inhibitor of phosphodiesterase, had no effect on the $\mathrm{P}_{3}$ hydrolyzing activity of h-prune.

Importantly, the metastasis suppressor protein, $\mathrm{nm} 23-\mathrm{H} 1$ that binds h-prune in vivo (3) markedly inhibited its $\mathrm{P}_{3}$ hydrolyzing activity, even at micromolar concentrations (Figure 3). The $\mathrm{IC}_{50}$ value measured for $\mathrm{nm} 23-\mathrm{H} 1$ also increased with $\mathrm{P}_{3}$ concentration (Table 3), suggestive of binding competition between $\mathrm{nm} 23-\mathrm{H} 1$ and the substrate. Moreover, $\mathrm{P}_{25}$ added to h-prune hydrolyzing $\mathrm{P}_{3}$ further increased $\mathrm{IC}_{50}$ for $\mathrm{nm} 23-\mathrm{H} 1$, indicating that the long polyphosphate also competes with nm23-H1 for h-prune binding.

\section{DISCUSSION}

Our results clearly demonstrate that polyphosphate hydrolysis is the major enzymatic function of h-prune, suggesting its significance in polyphosphate metabolism in animals. Inorganic polyphosphates (formed by three to hundreds of phosphate units) are present in all cells $(27,28)$, accounting for up to $10 \%$ of dry cell weight in yeast (29). Inorganic polyphosphates are not simply stores of phosphate and energy; they also have numerous regulatory functions (27-33). Organic polyphosphates are found in smaller quantities. Of these, adenosine $5^{\prime}$-tetra- and $5^{\prime}$-pentaphosphates are possibly among the most important organic polyphosphates identified to date (34). These compounds are involved in regulation of coronary vascular tone (35) and intraocular pressure (36) in mammals, and are strong inhibitors of dinucleoside tetraphosphate hydrolase (37). The cellular levels of both polyphosphate types are largely determined by the activity of the depolymerizing enzyme, exopolyphosphatase, which has been characterized in bacteria and lower eukaryotes. Exopolyphosphatase activity capable of converting inorganic $(38,39)$ and organic $(40,41)$ polyphosphates was additionally evident in mammalian tissues, but, surprisingly, no gene exactly matching known PPXs is found in mammalian genomes. Based on our findings, we infer that this activity belongs to h-prune, thus classifying the protein as the first known animal exopolyphosphatase. Interestingly, all completely sequenced animal genomes contain genes for h-prune subfamily proteins, while none contains gene(s) for yeast-type PPX. 
Functionally, h-prune is more similar to the three previously characterized PPXs $(10,22,23,42,43)$ than to PPases. Both h-prune and the PPXs favor $\mathrm{Mg}^{2+}$ or $\mathrm{Co}^{2+}$ as the metal cofactor and exhibit very similar $\mathrm{Mg}^{2+}$ activation profiles (compare Figure 2 with Figure 3 in ref 15) and identical stoichiometries of reaction complexes (Scheme 1). Both enzymes bind up to two metal ions per substrate, in contrast to PPase, which requires three to four metal ions (44). Furthermore, PPase differs from h-prune and PPXs in requiring transition metals for maximal activity (21). Both h-prune and PPXs $(10,42,43)$ hydrolyze inorganic and organic polyphosphates, but not $\mathrm{PP}_{\mathrm{i}}$. In contrast, PPase is inactive with polyphosphates longer than $\mathrm{PP}_{\mathrm{i}}(21)$. With respect to polyphosphate chain length preference, h-prune resembles PPXs from L. major (22) and T. cruzi (23), which also favor short-chain polyphosphates, unlike $s c$ PPX, which does not discriminate among polyphosphates of different lengths $(10,42)$. Cells containing short-chain PPXs are expected to have additional enzymes to metabolize long polyphosphates. Remarkably, mammalian cells possess endopolyphosphatase activity (45), allowing efficient degradation of long polyphosphates in cooperation with short-chain PPX.

Previous analyses $(3,18)$ placed PPXs and prunes into separate subfamilies, based on two motifs, DHH and DHR (going from $\mathrm{N}$ - to $\mathrm{C}$-terminus) in prune sequences instead of DHN and DHH of PPXs, respectively. Those analyses, however, included only the two theretofore known h-prunelike sequences (from $H$. sapiens and D. melanogaster) and implied different enzymatic activities of prune (phosphodiesterase) and PPX. Our current sequence analysis, using a much larger set of sequences that became available recently, indicates more variation in these motifs. Furthermore, our mutational analysis shows that such a variation is tolerable within one protein. Finally, identification of h-prune as a PPX breaks the functional border between h-prune and common PPXs. These findings make it likely that all or most of the 37 non-PPase sequences of family 2 of the DHH superfamily (Figure 1) are in fact PPXs. This group may thus be more uniform in terms of core structure and activity than previously believed. Considering the C-terminal extension, however, h-prune and its 13 closest homologues are clearly a more evolved PPX subfamily, regulated by binding to specific protein partners, like nm23-H1. This additional function appears to be called for in vertebrates.

Earlier studies show that h-prune exhibits low phosphodiesterase activity $(\sim 1 / 3500$ th of its exopolyphosphatase activity), hydrolyzing cAMP with a low $K_{\mathrm{m}}$ value of $0.9 \mu \mathrm{M}$ (3). This reaction hardly occurs at the exopolyphosphatase active site of h-prune, since neither cAMP (at a concentration exceeding $K_{\mathrm{m}}$ by 330 -fold) nor dipyridamole inhibit $\mathrm{P}_{3}$ hydrolysis. The theory that the phosphodiesterase activity is a side reaction of $\mathrm{h}$-prune preparations is additionally supported by the observations that h-prune shares no homology with any of the nearly 300 phosphodiesterase sequences from mammalian genomes.

H-prune has been shown to favor metastasis by binding and thus inactivating the antimetastatic protein nm23-H1 (7). Our new findings implicate polyphosphates as important modulators of this interaction. We found that increasing the concentration of the shortest polyphosphate, $\mathrm{P}_{3}$, decreases the stability of the h-prune-nm23-H1 complex, as character- ized by $\mathrm{IC}_{50}$ (Table 3 ). This effect presumably results from $\mathrm{P}_{3}$ binding to the exopolyphosphatase active site of h-prune. The long-chain polyphosphates that prevail in cells (28) should have the same or even greater effect when bound to this site, as suggested by the increased $\mathrm{IC}_{50}$ for $\mathrm{nm} 23-\mathrm{H} 1$ in the presence of $\mathrm{P}_{25}$ (Table 3). This mechanism is supported by recent reports showing that long-chain inorganic polyphosphates block pulmonary metastasis of melanoma cells in vivo (46) and induce apoptosis of several cancer cells but not normal cells in vitro (30).

In summary, h-prune displays novel exopolyphosphatase activity, exceeding its reported phosphodiesterase activity by 4 orders of magnitude, and is the first characterized member of a predicted subfamily of exopolyphosphatases in higher eukaryotic organisms, including mammals. Given the novel enzymatic activity of h-prune and its ability to bind polyphosphates, elucidation of the role of h-prune in cancer metastasis may eventually divulge new potential pathways and drugs to inhibit its recognized prometastatic action.

\section{ACKNOWLEDGMENT}

We thank Prof. Aldo Galeone for providing the $\mathrm{AP}_{4}$ used in preliminary studies and Dr. Livia Garzia for research support.

\section{SUPPORTING INFORMATION AVAILABLE}

A phylogenetic tree of family 2 of the DHH superfamily of proteins (Figure 1S). This material is available free of charge via the Internet at http://pubs.acs.org.

\section{REFERENCES}

1. Zollo, M., Andrè, A., Cossu, A., Sini, M. C., D’Angelo, A., Marino, N., Budroni, M., Tanda, F., Arrigoni, G., and Palmieri, G. (2005) Overexpression of h-prune in breast cancer is correlated with advanced disease status. Clin. Cancer Res. 11, 199-205.

2. Oue, N., Yoshida, K., Noguchi, T., Sentani, K., Kikuchi, A., and Yasui, W. (2007) Increased expression of h-prune is associated with tumor progression and poor survival in gastric cancer. Cancer Sci. 98, 1198-1205.

3. D’Angelo, A., Garzia, L., André, A., Carotenuto, P., Aglio, V., Guardiola, O., Arrigoni, G., Cossu, A., Palmieri, G., Aravind, L., and Zollo, M. (2004) Prune cAMP phosphodiesterase binds nm23$\mathrm{H} 1$ and promotes cancer metastasis. Cancer Cell 5, 137-149.

4. D’Angelo, A., and Zollo, M. (2004) Unraveling genes and pathways influenced by H-prune PDE overexpression: a model to study cellular motility. Cell Cycle 3, 758-761.

5. Garzia, L., Roma, C., Tata, N., Pagnozzi, D., Pucci, P., and Zollo, M. (2006) H-prune-nm23-H1 protein complex and correlation to pathways in cancer metastasis. J. Bioenerg. Biomembr. 38, 205213.

6. Kobayashi, T., Hino, S., Oue, N., Asahara, T., Zollo, M., Yasui, W., and Kikuchi, A. (2006) Glycogen synthase kinase 3 and h-prune regulate cell migration by modulating focal adhesions. Mol. Cell. Biol. 26, 898-911.

7. Marino, N., and Zollo, M. (2007) Understanding h-prune biology in the fight against cancer. Clin. Exp. Metastasis 24, 637-645.

8. Aravind, L., and Koonin, E. V. (1998) A novel family of predicted phosphoesterases includes Drosophila prune protein and bacterial RecJ exonuclease. Trends Biochem. Sci. 23, 17-19.

9. Lovett, S. T., and Kolodner, R. D. (1989) Identification and purification of a single-stranded-DNA-specific exonuclease encoded by the recJ gene of Escherichia coli. Proc. Natl. Acad. Sci. U.S.A. $86,2627-2631$.

10. Wurst, H., and Kornberg, A. (1994) A soluble exopolyphosphatase of Saccharomyces cerevisiae. Purification and characterization. J. Biol. Chem. 269, 10996-11001.

11. Young, T. W., Kuhn, N. J., Wadeson, A., Ward, S., Burges, D., and Cooke, G. D. (1998) Bacillus subtilis ORF yybQ encodes a manganese-dependent inorganic pyrophosphatase with distinctive 
properties: the first of a new class of soluble pyrophosphatase. Microbiology 144 (Pt 9), 2563-2571.

12. Shintani, T., Uchiumi, T., Yonezawa, T., Salminen, A., Baykov, A. A., Lahti, R., and Hachimori, A. (1998) Cloning and expression of a unique inorganic pyrophosphatase from Bacillus subtilis: Evidence for a new family of enzymes. FEBS Lett. 439, 263-266.

13. Middelhaufe, S., Garzia, L., Ohndorf, U. M., Kachholz, B., Zollo, M., and Steegborn, C. (2007) Domain mapping on the human metastasis regulator protein h-prune reveals a C-terminal dimerization domain. Biochem. J. 407, 199-205.

14. Baykov, A. A., and Avaeva, S. M. (1981) A simple and sensitive apparatus for continuous monitoring of orthophosphate in the presence of acid-labile compounds. Anal. Biochem. 116, 1-4.

15. Tammenkoski, M., Moiseev, V. M., Lahti, M., Ugochukwu, E., Brondijk, T. H. C., White, S. A., Lahti, R., and Baykov, A. A. (2007) Kinetic and mutational analyses of the major cytosolic exopolyphosphatase from Saccharomyces cerevisiae. J. Biol. Chem. 282, 9302-9311.

16. Chenna, R., Sugawara, H., Koike, T., Lopez, R., Gibson, T. J., Higgins, D. G., and Thompson, J. D. (2003) Multiple sequence alignment with the Clustal series of programs. Nucleic Acids Res. 31, 3497-3500.

17. Kumar, S., Tamura, K., and Nei, M. (2004) MEGA3: Integrated software for Molecular Evolutionary Genetics Analysis and sequence alignment. Briefings Bioinf. 5, 150-163.

18. Ugochukwu, E., Lovering, A. L., Mather, O. C., Young, T. W., and White, S. A. (2007) The crystal structure of the cytosolic exopolyphosphatase from Saccharomyces cerevisiae reveals the basis for substrate specificity. J. Mol. Biol. 371, 1007-1021.

19. Merckel, M. C., Fabrichniy, I. P., Salminen, A., Kalkkinen, N., Baykov, A. A., Lahti, R., and Goldman, A. (2001) Crystal structure of Streptococcus mutans pyrophosphatase: A new fold for an old mechanism. Structure 9, 289-297.

20. Ahn, S., Milner, A., Fütterer, K., Konopka, M., Ilias, M., Young, T. W., and White, S. A. (2001) The "open" and "closed" structures of the type-C inorganic pyrophosphatases from Bacillus subtilis and Streptococcus gordonii. J. Mol. Biol. 313, 797-811.

21. Parfenyev, A. N., Salminen, A., Halonen, P., Hachimori, A., Baykov, A. A., and Lahti, R. (2001) Quaternary structure and metal ion requirement of family II pyrophosphatases from Bacillus subtilis, Streptococcus gordonii, and Streptococcus mutans. J. Biol. Chem. 276, 24511-24518.

22. Rodrigues, C. O., Ruiz, F. A., Vieira, M., Hill, J. E., and Docampo, R. (2002) An acidocalcisomal exopolyphosphatase from Leishmania major with high affinity for short chain polyphosphate. J. Biol. Chem. 277, 50899-50906.

23. Fang, J., Ruiz, F. A., Docampo, M., Luo, S., Rodrigues, J. S., Motta, L. S., Rohloff, P., and Docampo, R. (2007) Overexpression of a $\mathrm{Zn}^{2+}$-sensitive soluble exopolyphosphatase from Trypanosoma cruzi depletes polyphosphate and affects osmoregulation. J. Biol. Chem. 282, 32501-32510.

24. Halonen, P., Tammenkoski, M., Niiranen, L., Huopalahti, S., Parfenyev, A. N., Goldman, A., Baykov, A. A., and Lahti, R. (2005) Effects of active site mutations on the metal binding affinity, catalytic competence, and stability of the family II pyrophosphatase from Bacillus subtilis. Biochemistry 44, 4004-4010.

25. Konopka, M. A., White, S. A., and Young, T. W. (2002) Bacillus subtilis inorganic pyrophosphatase: The $\mathrm{C}$-terminal signature sequence is essential for enzyme activity and conformational integrity. Biochem. Biophys. Res. Commun. 290, 806-812.

26. Volk, S. E., Baykov, A. A., Duzhenko, V. S., and Avaeva, S. M (1982) Kinetic studies on the interactions of two forms of inorganic pyrophosphatase of heart mitochondria with physiological ligands. Eur. J. Biochem. 125, 215-220.

27. Kornberg, A., Rao, N. N., and Ault-Riché, D. (1999) Inorganic polyphosphate: A molecule of many functions. Annu. Rev. Biochem. 68, 89-125.
28. Kulaev, I. S., and Kulakovskaya, T. V. (2000) Polyphosphate and phosphate pump. Annu. Rev. Microbiol. 54, 709-734.

29. Kulaev, I. S., Vagabov, V. M., and Kulakovskaya, T. V. (2004) The Biochemistry of Inorganic Polyphosphates, John Wiley \& Sons, Ltd., West Sussex.

30. Hernandez-Ruiz, L., González-García, I., Castro, C., Brieva, J. A., and Ruiz, F. A. (2006) Inorganic polyphosphate and specific induction of apoptosis in human plasma cells. Haematologica 91, $1180-1186$

31. Kuroda, A., Nomura, K., Ohtomo, R., Kato, J., Ikeda, T., Takiguchi, N., Ohtake, H., and Kornberg, A. (2001) Role of inorganic polyphosphate in promoting ribosomal protein degradation by the Lon protease in E. coli. Science 293, 705-708.

32. Zhang, H., Gómez-García, M. R., Brown, M. R., and Kornberg, A. (2005) Inorganic polyphosphate in Dictyostelium discoideum: Influence on development, sporulation, and predation. Proc. Natl. Acad. Sci. U.S.A. 102, 2731-2735.

33. Smith, S. A., Mutch, N. J., Baskar, D., Rohloff, P., Docampo, R., and Morrissey, J. H. (2006) Polyphosphate modulates blood coagulation and fibrinolysis. Proc. Natl. Acad. Sci. U.S.A. 103, 903908.

34. Zamecnik, P., and Stephenson, M. (1969) In The Role of Nucleotides for the Function and Conformation of Enzymes (Kalckar, H., Klenow, H., Munch-Peterson, G., Ottesen, M., and Thaysen, J., Eds.), pp 276-291, Elsevier, Munksgaard.

35. Westhoff, T., Jankowski, J., Schmidt, S., Luo, J., Giebing, G., Schlüter, H., Tepel, M., Zidek, W., and van der Giet, M. (2003) Identification and characterization of adenosine $5^{\prime}$-tetraphosphate in human myocardial tissue. J. Biol. Chem. 278, 17735-17740.

36. Pintor, J., Peláez, T., and Peral, A. (2004) Adenosine tetraphosphate, Ap4, a physiological regulator of intraocular pressure in normotensive rabbit eyes. J. Pharmacol. Exp. Ther. 308, 468-473.

37. Vallejo, C. G., Sillero, M. A., and Sillero, A. (1974) Diguanosinetetraphosphate guanylohydrolase in Artemia salina. Biochim. Biophys. Acta 358, 117-125.

38. Lorenz, B., Leuck, J., Köhl, D., Muller, W. E., and Schröder, H. C. (1997) Anti-HIV-1 activity of inorganic polyphosphates. J. Acquired Immune Defic. Syndr. 14, 110-118.

39. Leyhausen, G., Lorenz, B., Zhu, H., Geurtsen, W., Bohnensack, R., Müller, W. E., and Schröder, H. C. (1998) Inorganic polyphosphate in human osteoblast-like cells. J. Bone Miner. Res. 13, 803-812.

40. Small, G. D., and Cooper, C. (1966) Purification and properties of nucleoside tetraphosphate hydrolase from rabbit muscle. Biochemistry 5, 14-26.

41. Guranowski, A., Starzyńska, E., Pietrowska-Borek, M., Jemielity, J., Kowalska, J., Darzynkiewicz, E., Thompson, M. J., and Blackburn, G. M. (2006) Methylene analogues of adenosine 5'tetraphosphate. Their chemical synthesis and recognition by human and plant mononucleoside tetraphosphatases and dinucleoside tetraphosphatases. FEBS J. 273, 829-838.

42. Lorenz, B., Müller, W. E., Kulaev, I. S., and Schröder, H. C. (1994) Purification and characterization of an exopolyphosphatase from Saccharomyces cerevisiae. J. Biol. Chem. 269, 22198-22204.

43. Kulakovskaya, T. V., Andreeva, N. A., and Kulaev, I. S. (1997) Adenosine-5' -tetraphosphate and guanosine-5' -tetraphosphate: New substrates of the cytosolic exopolyphosphatase of the yeast Saccharomyces cerevisiae. Biochemistry (Moscow) 62, 1051-1052.

44. Fabrichniy, I. O., Lehtiö, L., Tammenkoski, M., Zyryanov, A. B., Oksanen, E., Baykov, A. A., Lahti, R., and Goldman, A. (2007) A trimetal site and substrate distortion in a family II inorganic pyrophosphatase. J. Biol. Chem. 282, 1422-1431.

45. Kumble, K. D., and Kornberg, A. (1996) Endopolyphosphatases for long chain inorganic polyphosphate in yeast and mammals. J. Biol. Chem. 271, 27146-27151.

46. Han, K. Y., Hong, B. S., Yoon, Y. J., Yoon, C. M., Kim, Y.-K., Kwon, Y.-G., and Gho, Y. S. (2007) Polyphosphate blocks tumour metastasis via anti-angiogenic activity. Biochem. J. 406, 49-55.

BI8010847 